\title{
SORPTION DYNAMICS OF DIRECT ORANGE 26 DYE ONTO A CORNCOB PLANT SORBENT
}

\author{
DYNAMIKA SORPCJI BARWNIKA DIRECT ORANGE 26 \\ NA SORBENCIE ROŚLINNYM - KOLBACH KUKURYDZY
}

\begin{abstract}
The azo dye and plant-derived sorbent system was investigated in this paper. Direct Orange 26 azo dye was acquired from Boruta-Zachem Kolor Sp. z o.o. Chemically modified granulated corncobs obtained from Chipsi Mais Germany were used as the biosorbent. The changes in the dye and sorbent concentrations with time were measured and used for further calculations. The experiments were carried out in a laboratory fixed bed column. Breakthrough curves were plotted for different initial concentrations, volumetric flow rates and bed heights. Sorption dynamics was described by a model presented in the literature. It was demonstrated that Infrared analysis of the system allows to determine the nature of the dye-sorbent bond. It was found that corncobs can be used as a promising sorbent material.
\end{abstract}

Keywords: azo dye, corncobs, sorption dynamics, fixed bed column

\section{Introduction}

Water is essential for life and economy. It is used for consumption, personal hygiene and it is required for the development of industry, farming and other sectors. At present, it is extremely important to maintain the standards of water quality set by applicable regulations and eliminate harmful substances from wastewater before it is discharged to the ecosystem. Technology options in water treatment include oxidising, ion exchange, adsorption, extraction, coagulation, sedimentation, ultrafiltration, neutralisation etc. [1].

Despite progress in technology and the use of modern equipment facilities, the textile industry is still very water intensive. As a result, vast amounts of wastewater are produced that cause environmental damage. In the textile industry, wastewater quality composition largely depends on which of the tens of thousands of dyes available on the market are used [2]. Effluents are salt laden, alkaline and most importantly, have intense colours. They are produced by the dyeing industry are decoloured primarily using synthetic ion-exchange beds which are highly effective. However, they are costly and difficult to dispose of. As a result, researchers are now exploring the potential to use natural waste products as sorbents (eg rye straw, vegetable peels, grain seed hulls, algae or biomass in a broad sense

${ }^{1}$ Faculty of Process and Environmental Engineering, Lodz University of Technology, ul. Wólczańska 213, 90-924 Łódź, Poland, phone +48 426313788

*Corresponding author: elwira.tomczak@p.lodz.pl 
of the term) [3-10]. They are relatively cheap and biodegradable which makes them an attractive alternative to synthetic substances.

In this paper, adsorption of Direct Orange 26 azo dye onto a plant sorbent ie granulated corncobs was analysed. After initial studies with raw and boiled cobs, further experiments involved cobs which had been chemically pretreated with a view to increasing their sorption capacity. Experiments were carried out to determine sorption kinetics and equilibrium based on the changes of dye concentration in the solution and in the sorbent. The primary goal of the study were sorption dynamics experiments conducted in the column packed with a modified sorbent.

The parameters analysed were: sorbent-dye solution contact time, bed breakthrough and saturation time. Based on the data obtained, the efficiency of Direct Orange 26 azo dye removal was determined for different process parameters. The results were described mathematically using a model proposed in the literature that describes the change in the amount of dye adsorbed on the bed in the column $q[\mathrm{mg} / \mathrm{g}]$ based on the obtained breakthrough curves, ie $C=f(t)$.

\section{Materials}

The dye used for the study was supplied by Boruta-Zachem Kolor Sp. z o.o. in Zgierz and belongs to a group of azo dyes. Chemical structure of the dye is presented in Figure 1.

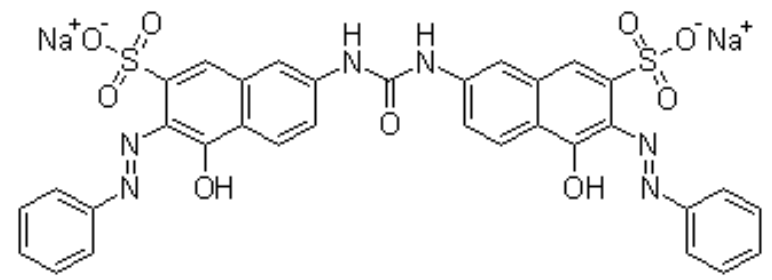

Fig. 1. Molecular structure of Direct Orange 26, molecular formula: $\mathrm{C}_{33} \mathrm{H}_{22} \mathrm{~N}_{6} \mathrm{Na}_{2} \mathrm{O}_{9} \mathrm{~S}_{2}, \mathrm{MW}=756.67$

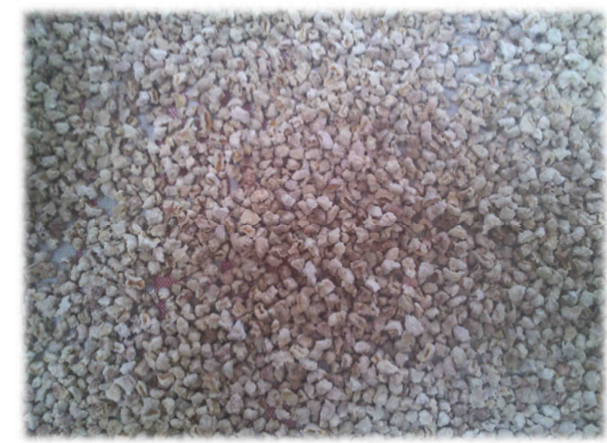

Fig. 2. Granulated corncobs

Granulated corncobs were used as a sorbent. Cobs are the thick, hard central core of maize. They are a lignocellulosic material composed of $44-45 \%$ cellulose, $31-40 \%$ hemicellulose, and $8-15 \%$ lignin $[11,12]$. Corncobs used in the study were acquired from 
CHIPSI MAIS Germany. They were hard granules of the mean size of approximately $0.005 \mathrm{~m}$, humidity of approximately $10 \%$, and density of $438.8 \mathrm{~kg} / \mathrm{m}^{3}$. Figures 2 and 3 show the granulated sorbent and the photo of its surface. Apart from being used for dye sorption, corncobs are also reported to be widely used for removal of heavy metals from aqueous solutions [13-16]. Corncobs are also equally commonly used to obtain activated carbon [17-21]. Activated carbon obtained from corncobs is used to adsorb several water contaminants such as methylene glycol [22], chlorophenol [23], dyes [24] or heavy metal ions $[16,25-27]$.

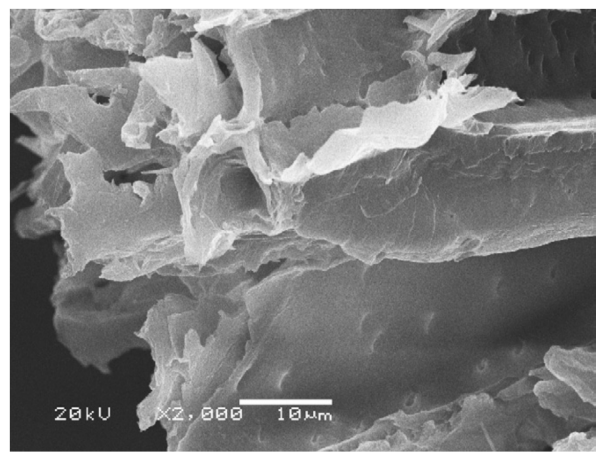

Fig. 3. SEM photo of corncob surface (2000x) [26]

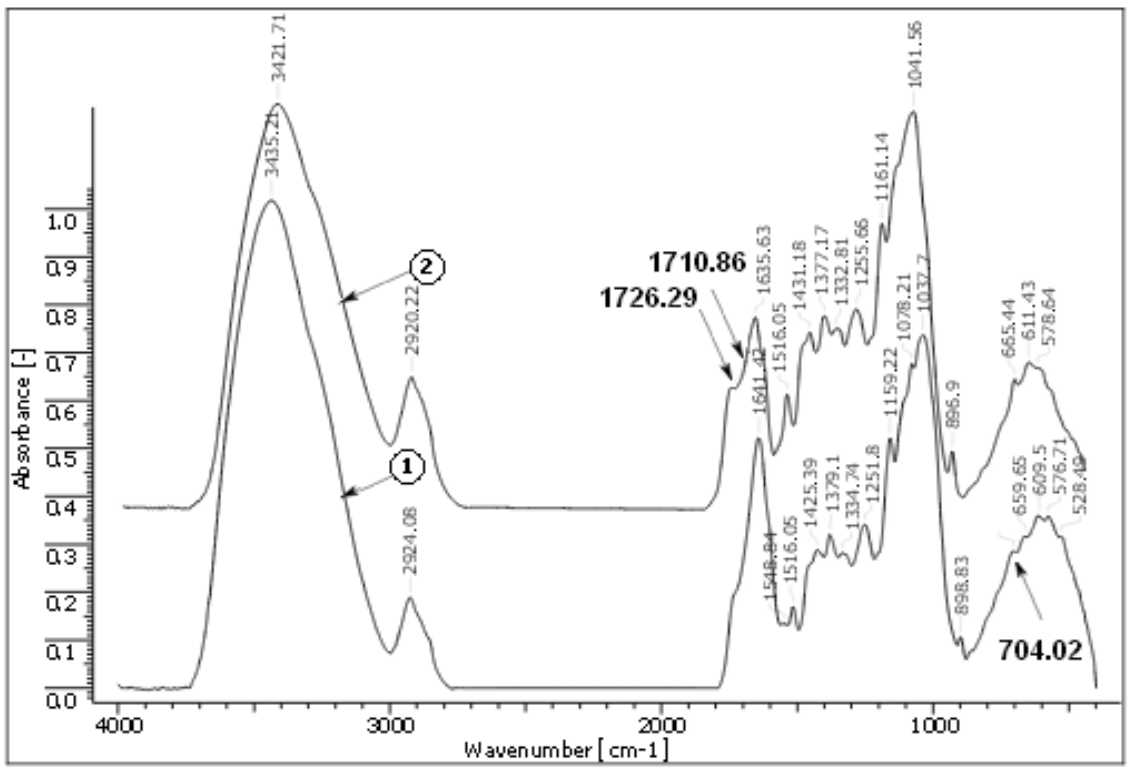

Fig. 4. FTIR spectra for: 1) corncob, 2) corncob with Reactive Orange 16 [28]

Infrared analysis of the sorbent is used both prior and after dye adsorption process to explore the mechanism of dye compound binding onto the sorbent. This allows to observe 
the modifications and bonds between the lignocellulosic complex of the biosorbent and the adsorbed contaminant.

Literature [28] describes the mechanism of Reactive Orange 16 azo dye binding onto corncobs (at $\mathrm{pH}=1$ ). Figure 3 compares the spectra for corncobs prior to and after dye adsorption. Specific bands can be observed at 1710.86 and $1726.29 \mathrm{~cm}^{-1}$, which indicates that ionic bonds are formed between lignin and the dye. At acidic $\mathrm{pH}$, due to the presence of hydroxyl groups of the side chain, lignin can be converted into conjugated structures with deficit electron centre $(\delta+)$, as shown by the band at $704.02 \mathrm{~cm}^{-1}$ (none on line 2). The authors conclude that FTIR spectra suggest a combined sorption mechanism being the result of ion exchange interactions and physical sorption.

The authors [29] report on the absorption spectra of dyes for several cheap plant sorbents such as birch chips, rice straw, hemp fibre and cellulose. Figure 5 shows a comparison of absorption spectra for cellulose as the sorbent and different azo dyes. A similar relationship was observed for cellulose and rye straw with the exception of Direct Orange 26, in which case the spectrum is totally different and new absorption bands appear (that were observed neither for the dye nor for the material itself). It means that the dye reacts with the molecular entities in the layer. Detailed analysis indicates the formation of assemblies such as sulphonic acids, thioketones (sulphoketonic forms - partially oxidised to acids) and acid esters (reciprocal reaction products).

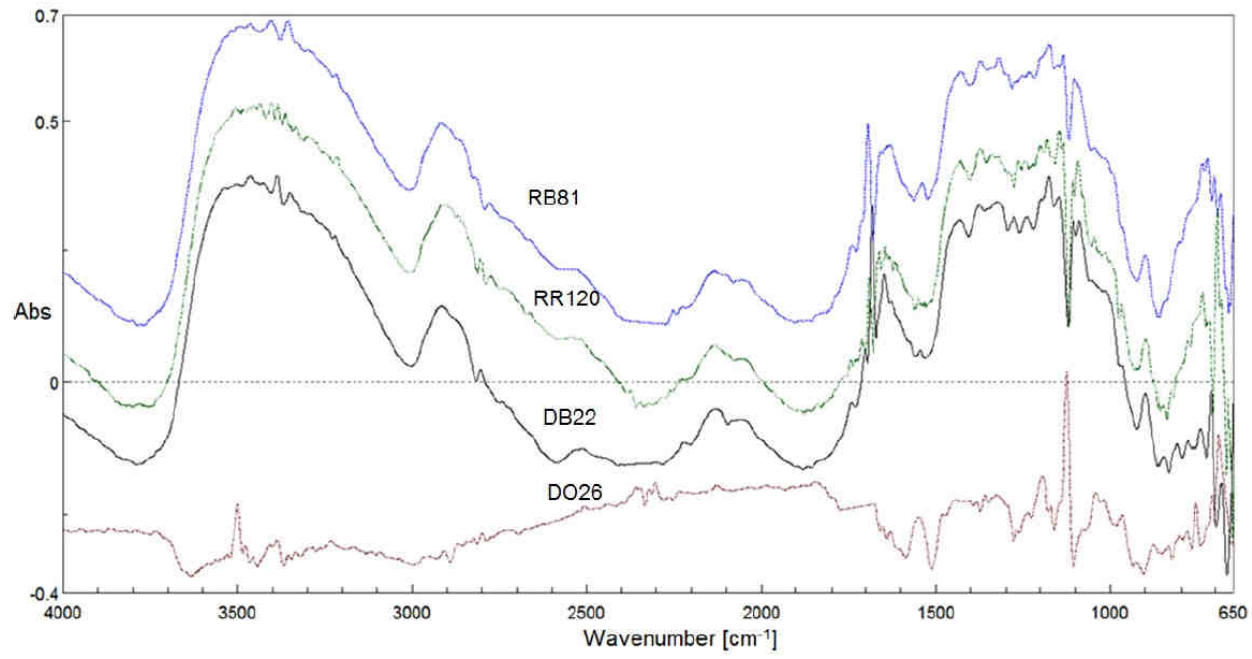

Fig. 5. Comparison of IR spectra obtained for cellulose after adsorption of four dyes: Reactive Blue 81, Reactive Red 120, Direct Black 22, Direct Orange 26 [29]

Dye binding to the sorbent may be the result of weak van der Waals forces and strong ionic exchange interactions between ionised sulfonic groups of the dye and sorbent surface as per the following formula [28]:

$$
\text { Corncob }-\mathrm{OH}+\mathrm{H}^{+}+\mathrm{O}_{3} \mathrm{~S}-\text { Dye }=\text { Corncob }-\mathrm{OH}_{2}{ }^{+}+\mathrm{H}^{+}+\mathrm{O}_{3} \mathrm{~S}-\text { Dye }
$$




\section{Test method}

Granulated corn cobs were washed and boiled for $3 \mathrm{~h}$ in a pressure cooker $\left(130^{\circ} \mathrm{C}\right)$. To increase their sorption capacity, the corncobs were etched with $10 \% \mathrm{H}_{2} \mathrm{SO}_{4}$ for $5 \mathrm{~h}$ at $60^{\circ} \mathrm{C}$. Following chemical pretreatment, the granulated corncobs were dried at $70^{\circ} \mathrm{C}$ for $2 \mathrm{~h}$. The procedure of chemical pretreatment was developed based on the previous experience with corncobs that had only been washed. Sorption equilibrium and kinetics studies were carried out at $T=25^{\circ} \mathrm{C}, \mathrm{pH}=5-6$. Five grams of dry weight sorbent were placed in glass flasks and $200 \mathrm{~cm}^{3}$ of the solution of dye concentration of $100-800 \mathrm{mg} / \mathrm{dm}^{3}$ was added. Flasks with the mixture were shaken mechanically in a water bath until adsorption equilibrium was reached. During the process, dye concentration in the water phase was measured using UV-vis Jasco V630 spectrophotometer at wavelength of $494 \mathrm{~nm}$. Based on experimental data, with known initial concentration $C_{0}$ and equilibrium concentration $C_{e}$, sorption capacity $q_{e}$ was determined for the solution using the following formula:

$$
q_{e}=\frac{V}{m}\left(C_{0}-C_{e}\right)
$$

where: $C_{0}$ and $C_{e}$ - initial and equilibrium concentration of dye in the solution $\left[\mathrm{mg} / \mathrm{dm}^{3}\right]$, $q_{e}$ - equilibrium concentration of dye in the adsorbent, sorption $[\mathrm{mg} / \mathrm{g}], V$ - solution volume $\left[\mathrm{dm}^{3}\right]$, $m$ - adsorbent mass [g].

Sorption kinetics results are presented in Figure 6.

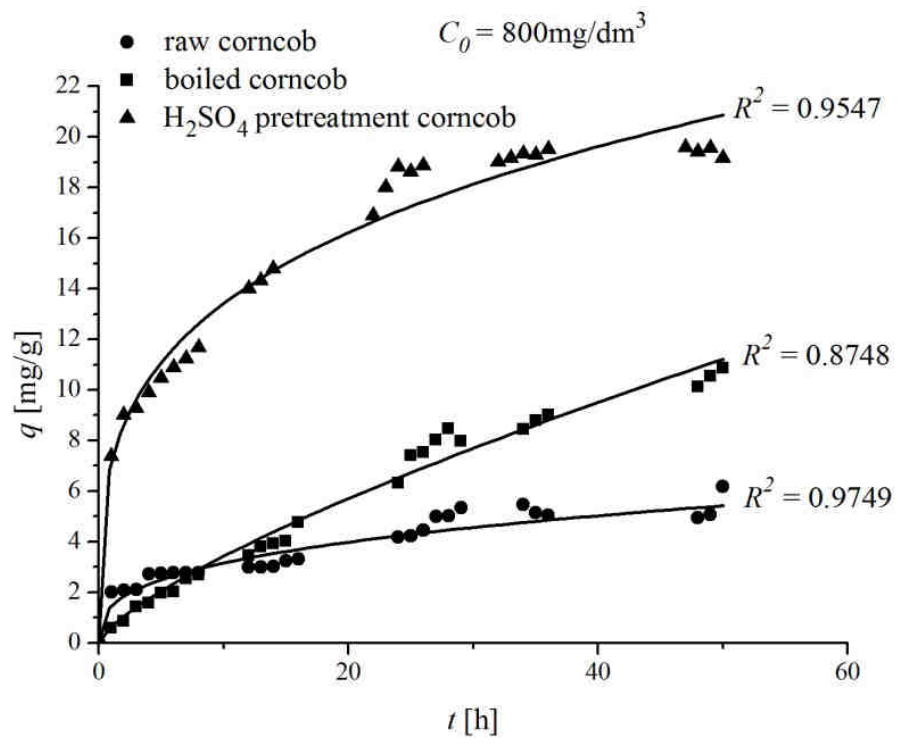

Fig. 6. Dye sorption kinetics for different methods of sorbent pre-treatment

Adsorption dynamics studies were conducted in a laboratory column of $3.45 \mathrm{~cm}$ in diameter and $70 \mathrm{~cm}$ in length (Fig. 7) packed with granulated corncobs. Bed porosity was $\varepsilon=0.33$. Dye solution (flowing upwards) was fed with a dosing pump. Having passed through the bed, it was collected at predetermined intervals and analysed quantitatively using UV-Vis Jasco V630 spectrophotometer, $\mathrm{pH}$ and temperature of the dye solution was 
measured at the column inlet and outlet. Temperature stabilized at approximately $25^{\circ} \mathrm{C}$, and $\mathrm{pH}$ was approximately 5-6. Experiments were conducted for two initial concentrations of dye solution $C_{0}=50$ and $75 \mathrm{mg} / \mathrm{dm}^{3}$, four volumetric flow rates $Q=50,100,200$ and $400 \mathrm{~cm}^{3} / \mathrm{h}$ and two bed heights $H=59$ and $29 \mathrm{~cm}$, which corresponded to mass $m=165$ and $85 \mathrm{~g}$.

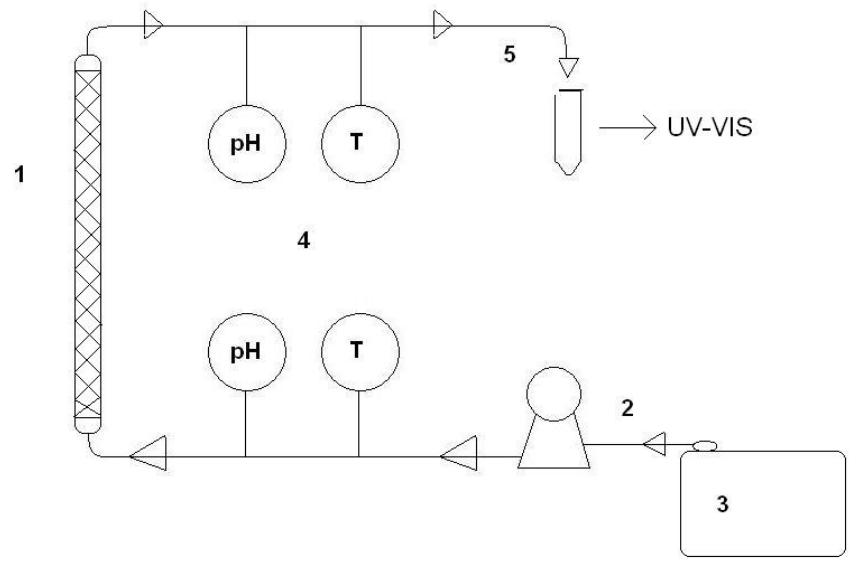

Fig. 7. Experimental setup: 1 - column, 2 - dosing pump, 3 - dye tank, 4 - temperature and $\mathrm{pH}$ measurements, 5 - sampling

\section{Mathematical description of sorption equilibrium}

Sorption equilibrium mathematical modelling is useful for analysing and designing adsorption systems. Dynamics description defines the change of the concentration of adsorbate in the solution and adsorbent over time and along the bed height. For the packed column it was assumed that the process was isothermal, the bed was uniform and constantly porous, adsorbate flow rate and feed solution concentration were constant.

To determine $q[\mathrm{mg} / \mathrm{g}]$, a formula was used that allows to calculate the content of the dye in the sorbent based on the model presented in [30]:

$$
q=\frac{\left(t_{i}-\int_{t_{0}}^{t_{i}} f(t) d t\right) \cdot Q \cdot C_{0}}{m}
$$

where: $q$ - adsorbed dye $[\mathrm{mg} / \mathrm{g}], Q$ - volumetric flow rate $\left[\mathrm{dm}^{3} / \mathrm{h}\right], C_{0}$ - initial concentration of the dye in the solution $\left[\mathrm{mg} / \mathrm{dm}^{3}\right], m$ - adsorbent mass $[\mathrm{g}], t_{i}$ - successive time moment $[\mathrm{h}]$.

In this case the volumetric mass transfer coefficient or in-pellet diffusion coefficient are not required, unlike in the case of solving the mass-balance equation for the column.

All calculations required to determine dye concentration in the sorbent $q[\mathrm{mg} / \mathrm{g}]$ were carried out using ORIGIN software with the following procedure employed: $C / C_{0}$ were graphed as a function of time and integrated. With the known integral values, the amount of dye adsorbed on the bed was calculated using the above model. 


\section{Interpretation of results}

The results of experiments and calculations are presented in Figures 8 and 9 .

Breakthrough curves are presented for various initial concentrations and four volumetric flow rates. Experiments were continued until inlet concentration equalled outlet concentration. Characteristic values were also marked which corresponded to the breakthrough and saturation concentration. For $C_{0}=50 \mathrm{mg} / \mathrm{dm}^{3}$ and for the lowest flow, sorption process lasted approximately 220 hours.

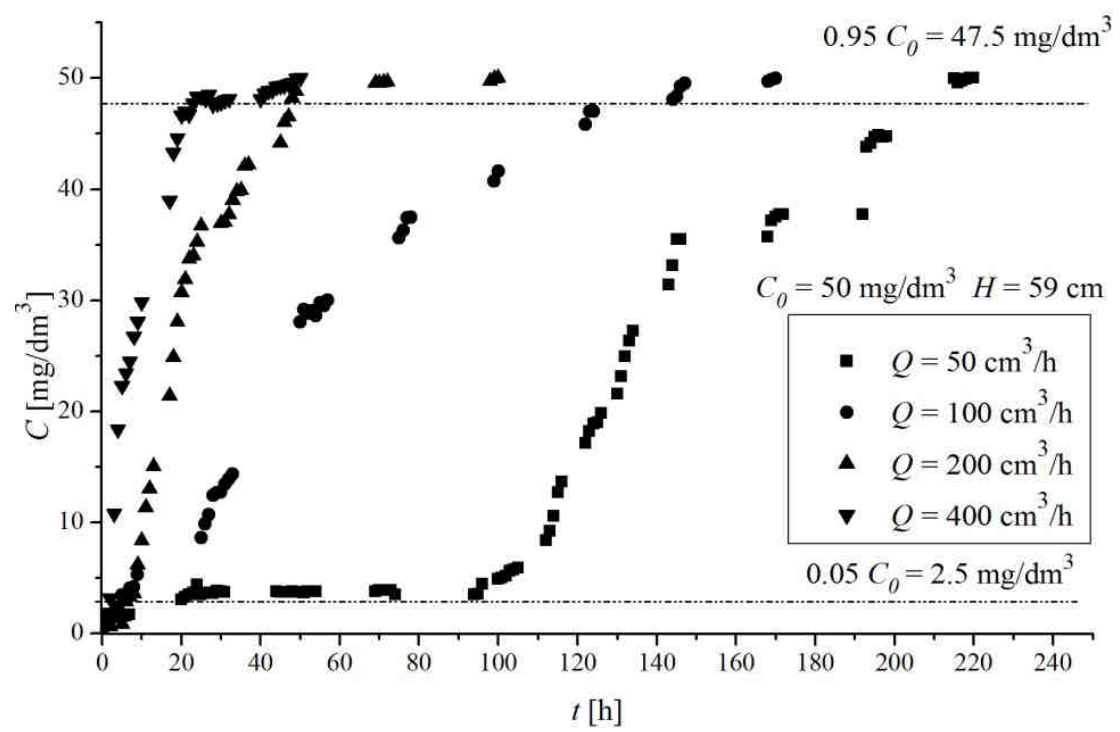

Fig. 8. Breakthrough curves for different volumetric flow rates

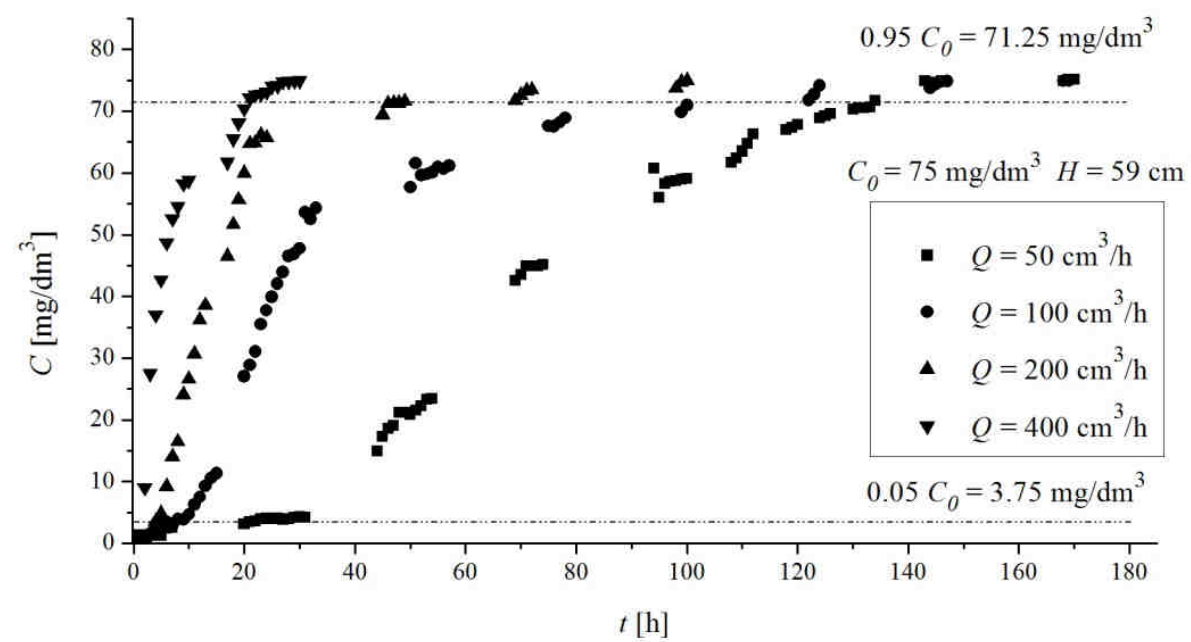

Fig. 9. Breakthrough curves for different volumetric flow rates 
Figure 10 shows the impact of bed height on breakthrough and saturation time and the corresponding concentrations for selected process parameters.

Equation (2) was used to calculate the amount of the dye adsorbed onto corncobs. Figure 11 shows some of modelling results for $C_{0}=75 \mathrm{mg} / \mathrm{dm}^{3}$ and different volumetric flow rates. Figures 12 and 13 show (for different parameters) the change of bed exploitation within the range from 100 to $0 \%$ which correlates with the amount of adsorbed dye once the solution is discoloured.

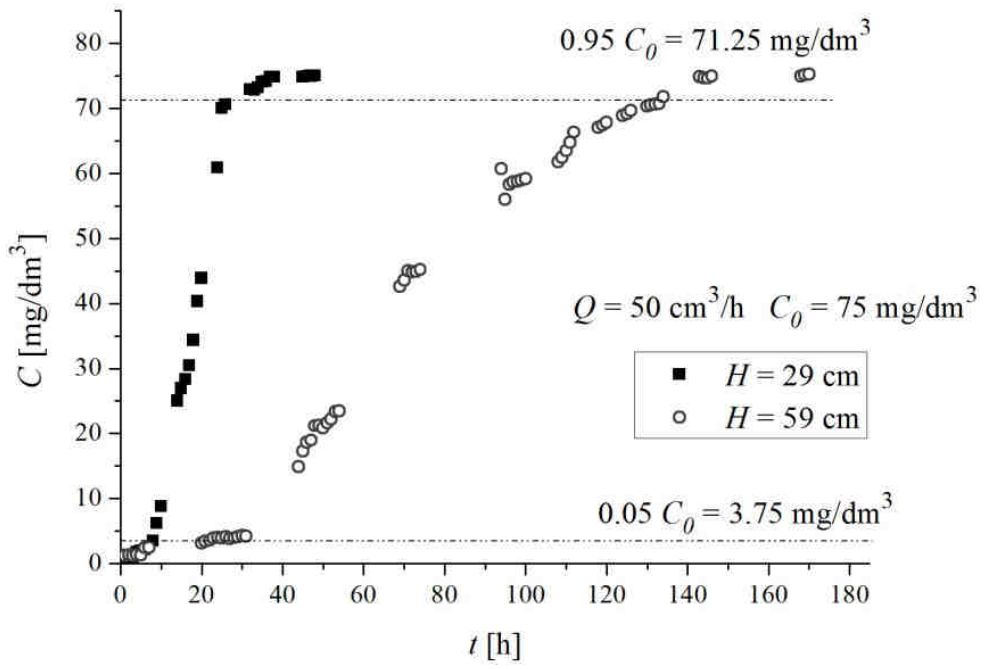

Fig. 10. Change of dye concentration with time in the column

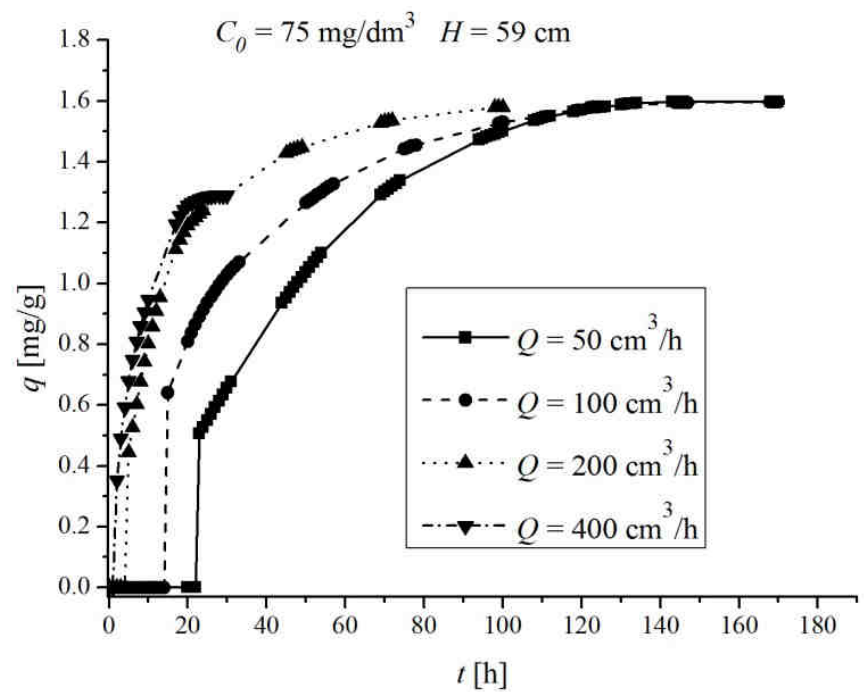

Fig. 11. Amount of dye adsorbed per sorbent unit mass with time 


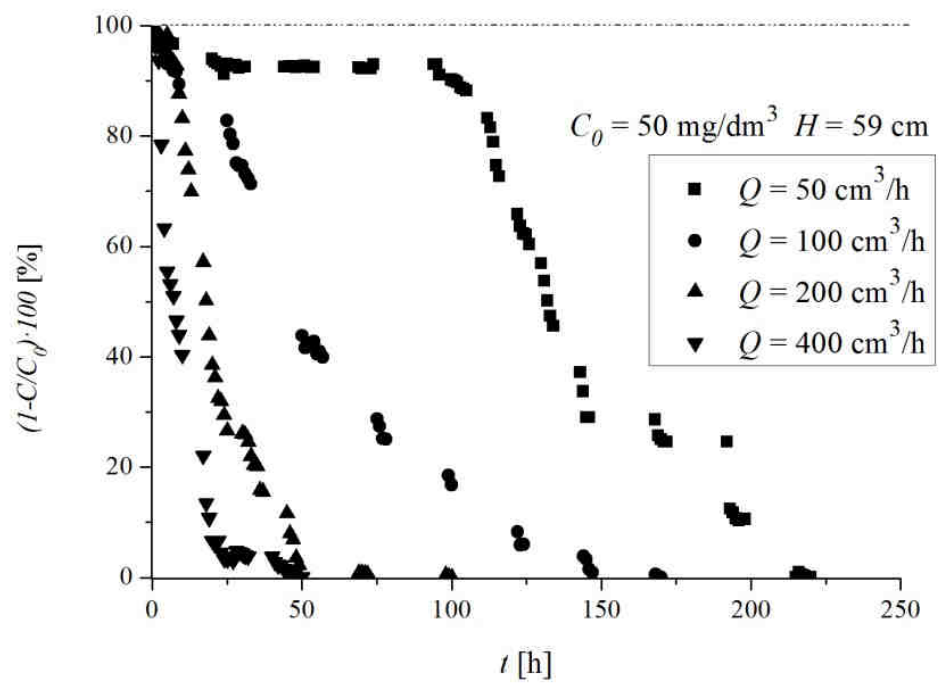

Fig. 12. Change of bed sorption capacity with time

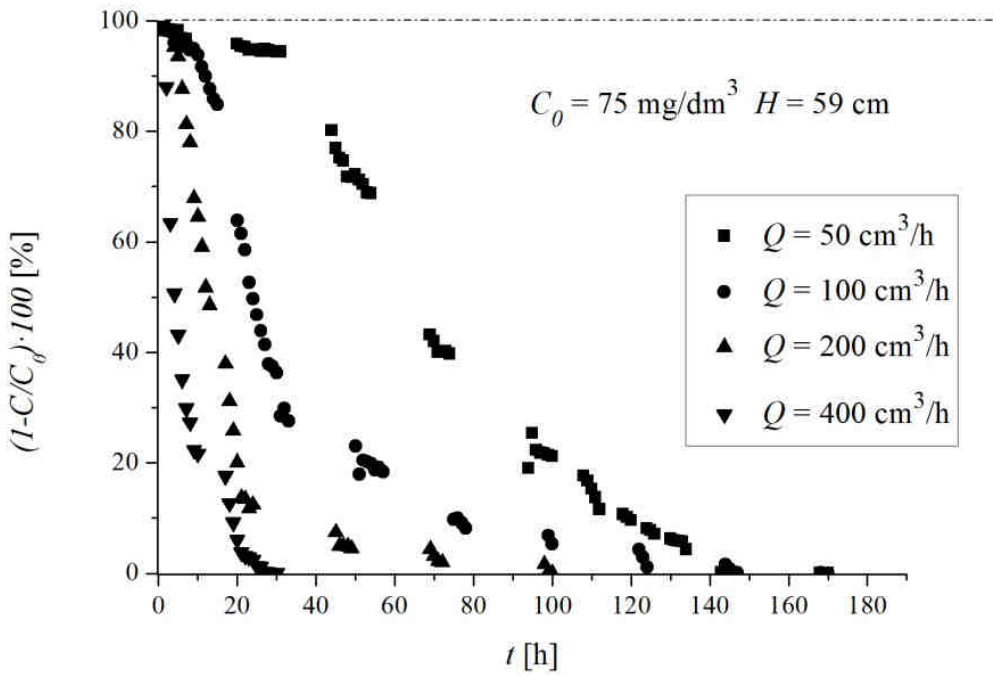

Fig. 13. Change of bed sorption capacity with time

\section{Summary}

The aim of the present paper was to determine sorption capacity of thermally and chemically pretreated granulated corncobs as a potential natural adsorbent to remove Direct Orange 26 azo dye from aqueous solutions. Based on literature reports it was assumed that corncobs, containing lignocellulosic complex, can adsorb dyes and other contaminants from aqueous solutions. 
Sorption capacity was assessed in experiments with fixed bed column and varying process parameters. It was shown that initial concentration and volumetric flow rate of the dye solution have a major impact on the results obtained in the analysis. Higher values implied shorter breakthrough and saturation times. A similar relation was observed for smaller bed height.

For mathematical description ie to determine the amount of the dye retained by the sorbent, a simple but effective mathematical model was used. Additionally, the availability of sorbent for the dye was determined which changed over the time of the experiment.

\section{Conclusions}

The aim of the present paper was to determine sorption capacity of thermally and chemically pretreated granulated corncobs as a potential natural adsorbent to remove Direct Orange 26 azo dye from aqueous solutions. Based on literature reports it was assumed that corncobs, containing lignocellulosic complex, can adsorb dyes and other contaminants from aqueous solutions.

Sorption capacity was assessed in experiments with fixed bed column and varying process parameters. It was shown that initial concentration and volumetric flow rate of the dye solution have a major impact on the results obtained in the analysis. Higher values implied shorter breakthrough and saturation times. A similar relation was observed for smaller bed height.

For mathematical description ie to determine the amount of the dye retained by the sorbent, a simple but effective mathematical model was used. Additionally, the availability of sorbent for the dye was determined which changed over the time of the experiment.

\section{References}

[1] Geise GM, Lee HS, Miller DJ, Freeman D, Mcgrath JE, Paul DR. Water purification by membranes: The role of polymer science. J Pol Sci 2010;48:1685-1718. DOI: 10.1002/polb.22037.

[2] Ahmad AL, Harris WA, Syafiie, Ooi BS. Removal of dye from wastewater of textile industry using membranes. J Tek. 2012:36;31-44. DOI: 10.11113/jt.v36.581.

[3] Tomczak ET, Kamiński W, Tosik P. Adsorption dynamics studies of azo dyes removal by biosorbent. Desalin Water Treat. 2014;55(10): 2669-2674. DOI: 10.1080/19443994.2014.939490.

[4] Tomczak ET, Kamiński W, Szczerkowska D. Fractional derivatives for description of sorption kinetics in the plant sorbent-metal ions system. Ecol Chem Eng S. 2013;20(3):499-506. DOI: 10.2478/eces-2013-0037.

[5] Crini G. Non-conventional low-cost adsorbents for dye removal: A review. Biores Technol. 2006;97:10611085. DOI: 10.1016/j.biortech.2005.05.001

[6] Vadivelan V, Kumar KV. Equilibrium, kinetics, mechanism, and process design for the sorption of methylene blue onto rice husk. J Colloid Interface Sci. 2005;286:90-100. DOI: 10.1016/j.jcis.2005.01.007.

[7] Wang Y, Gao BY, Yue WW, Yue QY. Adsorption kinetics of nitrate from aqueous solutions onto modified wheat residua. Colloids Surf A. Physicochem Eng Aspects. 2007;308:1-5. DOI: 10.1016/j.colsurfa.2007.05.014.

[8] Tan IAW, Ahmad AL, Hameed BH. Adsorption of basic dye on high-surface-area activated carbon prepared from coconut husk: Equilibrium, kinetic and thermodynamic studies. J Hazard Mater. 2008;154:337-346. DOI: 10.1016/j.jhazmat.2007.10.031.

[9] Sheng PX, Ting YP, Chen JP, Hong L. Sorption of lead, copper, cadmium, zinc, and nickel by Marine algal biomass: characterization of biosorptive capacity and investigation of mechanisms. J Colloid Interf Sci. 2004;275:131-141. DOI: 10.1016/j.jcis.2004.01.036.

[10] Rajfur M. Algae-heavy metals biosorbent. Ecol Chem Eng S. 2013;20:23-40. DOI: 10.2478/eces-2013-0002.

[11] Robinson T, Chandran B, Nigam P. Removal of dyes from an artificial textile dye effluent by two agricultural waste residues, corncob and barley husk. Environ Internat. 2002;28:29-33. DOI: $10.1016 / \mathrm{S} 0160-4120(01) 00131-3$. 
[12] Nada AAM, Mahdy A, El-Gendy AA. Spectroscopy and chemical studies of cation exchangers prepared from corn cobs. BioResources. 2009;4(3):1017-1031. http://ojs.cnr.ncsu.edu/index.php/BioRes/article/view/ BioRes_04_3_1017_Nada_ME_Spec_Chem_Cation_Eschangers_Corn_Cob/400.

[13] Fonseca-Correa F, Giraldo L, Moreno-Pirajan JC. Trivalent chromium removal from aqueous solution with physically and chemically modified corncob waste. J Analyt Appl Pyrolysis. 2013;101:132-141. DOI: 10.1016/j.jaap.2013.01.019.

[14] Shen J, Duvnjak Z. Adsorption kinetics of cupric and cadmium ions on corncob particles. Process Biochem. 2005;40:3446-3454. DOI: 10.1016/j.procbio.2005.02.016.

[15] Leyva-Ramos R, Bernal-Jacome LA, Acosta-Rodriguez I. Adsorption of cadmium(II) from aqueous solution on natural and oxidized corncob. Separation Purif Technol. 2005;45:41-49. DOI: 10.1016/j.seppur.2005.02.005.

[16] Nasiruddin Khan M, Farooq Wahab M. Characterization of chemically modified corncobs and its application in the removal of metal ions from aqueous solution. J Hazard Mater. 2007;6:237-244. DOI: 10.1016/j.jhazmat.2006.06.119.

[17] Zhang C, Geng Z, Cai M, Zhang J, Liu X, Xin H, et al. Microstructure regulation of super activated carbon from biomass source corncob with enhanced hydrogen uptake. Internat J Hydrogen En. 2013;38:9243-9250. DOI :10.1016/j.ijhydene.2013.04.163.

[18] El-Hendawy AA, Samra SE, Girgis BS. Adsorption characteristics of activated carbons obtained from corncobs. Colloids Surf A: Physicochem Eng Aspects. 2001;180:209-221. DOI: 10.1016/S0927-7757(00)00682-8.

[19] Tseng RL, Tseng SK. Pore structure and adsorption performance of the $\mathrm{KOH}$-activated carbons prepared from corncob. Desalination. 2011;280:1-13. DOI: 10.1016/j.jcis.2005.02.033.

[20] Sych NV, Trofymenko SI, Poddubnaya OI, Tsyba MM, Sapsay VI, Klymchuk DO, et al. Porous structure and surface chemistry of phosphoric acid activated carbon from corncob. Appl Surf Sci. 2012;261:75-82. DOI: 10.1016/j.apsusc.2012.07.084.

[21] Yong S, Webley PA. Preparation of activated carbons from corncob with large specific surface area by a variety of chemical activators and their application in gas storage. Chem Eng J. 2010;162:883-892. DOI: 10.1016/j.cej.2010.06.031.

[22] Aworn A, Thiravetyan P, Nakbanpote W. Preparation of $\mathrm{CO}_{2}$ activated carbon from corncob for monoethylene glycol adsorption. Colloids Surf A: Physicochem Eng Aspects. 2009;333:19-25. DOI: 10.1016/j.colsurfa.2008.09.021.

[23] Wu FCh, Wu PH, Tseng RL, Juang RS. Preparation of novel activated carbons from $\mathrm{H}_{2} \mathrm{SO}_{4}$-pretreated corncob hulls with $\mathrm{KOH}$ activation for quick adsorption of dye and 4-chlorophenol. J Environ Manage. 2011;92:708-713. DOI: 10.1016/j.jenvman.2010.10.003.

[24] Preethi S, Sivasamy A, Sivanesan S, Ramamurthi V, Swaminathan G. Removal of safranian basic dye from aqueos solutions by adsorptions onto corncob activated carbon. Eng Chem Res. 2006;45:7627-7632. DOI: 10.1021/ie0604122.

[25] Reddad Z, Gerente C, Andres Y, Le Cloirec P. Adsorption of several metal ions onto a low-cost biosorbent: Kinetic and equilibrium studies. Environ Sci Technol. 2002;36:2067-2073. DOI: 10.1021./es0102989.

[26] Sud D, Mahajan G, Kaur M.P. Agricultural waste material as potential adsorbent for sequestering heavy metal ions from aqueous solutions - A review. Biores Technol. 2008;99:6017-6027. DOI: 10.1016/j.biortech.2007.11.064.

[27] Tana G, Yuana H, Liub Y, Xiaoa D. Removal of lead from aqueous solution with native and chemically modified corncobs. J Hazard Mater. 2010;174:740-745. DOI: 10.1016/j.jhazmat.2009.09.114.

[28] Suteu D, Malutan T, Bilba D. Agricultural waste corn cob as sorbent for removing reactive dye orange 16: equilibrium and kinetic study. Cellulose Chem Technol. 2011;45:413-420. http://www.cellulosechemtechnol.ro/pdf/CCT45,5-6(2011)/p.413-420.pdf.

[29] Kamiński W, Tomczak E, Kuberski S. Sorption equilibrium of selected azo dyes onto low-cost sorbents. Global J Adv Pure Appl Sci. 2013;1:94-100. http://www.world-education-center.org/index.php/ paas/article/view/2184/3469.

[30] Chen JP, Yoon JT, Yiacoumi S. Effects of chemical and physical properties of influence on copper sorption onto activated carbon fixed-bed columns. Carbon. 2003;41:1635-1644. DOI: 10.1016/S0008-6223(03)00117-9. 